\title{
Settling debts in the supply chain: do prompt payment codes make a difference? A UK study
}

\begin{abstract}
Trade credit has only recently been taken seriously by business ethicists, despite the common practice of slow payment of suppliers and attempts by policymakers to improve supply chain behaviour. In the UK, initiatives have included the introduction of voluntary 'payment codes'. However, at the time to which our data relate, relatively few FTSE 100 companies had signed up. Furthermore, although signatories paid more quickly, the difference was not statistically significant. These two findings might appear to suggest that payment codes are ineffective. However, some companies were stating that they were following a code which was, in fact, defunct. Their payment speed was indistinguishable from non-signatories', but those that had signed the extant code paid significantly more quickly. Our findings therefore not only suggest that a payment code might indeed be effective in improving the operation of supply chains but also show a result relevant to codes of ethics more generally - that there might be signs that a company is not taking a code seriously, which we identify with the notion of hypocrisy. Given the appearance of a further prompt payment code in the UK and developments elsewhere, we make suggestions for further research in this developing area. The findings will be of interest to researchers of prompt payment and of codes of ethics, to those responsible for the management of trade credit, and to policymakers seeking to improve the efficiency of payments in supply chains.
\end{abstract}

\section{Key words}

Codes of ethics

Late payment

Payment codes

Prompt payment 
Supply chains

Trade credit

Trade creditors 


\section{Settling debts in the supply chain: do prompt payment codes make a difference? A UK study}

\section{Introduction}

Trade credit, and in particular the slow or late payment of suppliers, has only recently been considered seriously in the business ethics literature (Cowton \& San-Jose, 2017; pace Sorell \& Hendry, 1994), in spite of late payment being one of the most commonplace problems of business ethics, as Sorell and Hendry (1994) point out. Late payment is of great concern to many businesses, especially SMEs, which often find their finances unreasonably stretched, especially by powerful, large companies - sometimes to the extent that they go out of business, with harmful consequences for their owners, employees and other stakeholders (Cowton \& San-Jose, 2017). Slow payment itself can be extremely disruptive to supply chains which, with increased outsourcing and use of overseas contractors, have become increasingly lengthy and complex. Money can take a long time to reach the parties it is owed to, even though electronic payment systems should make the process much quicker than it used to be. Policymakers in some countries have, as a consequence, sought to reform custom and practice and bring about better payment behaviour. In the UK, this has included the introduction of voluntary 'payment codes', which aim to encourage companies to settle their debts to suppliers more promptly.

Trade credit arises when goods or services are provided by one company to another in the expectation that payment will be made at some future date, rather than immediately. It puts pressure on the supply chain in the form of strain on the finances of suppliers, who have had to undertake work and spend money in advance - possibly considerably in advance - of receiving payment. It puts suppliers in a vulnerable position as they wait to discover when, or even whether, they will be paid at the agreed time, notwithstanding the setting of payment terms underpinned by contract law. 
From the perspective of companies making purchases, being able to delay payment is, in effect, a source of finance at the expense of its suppliers; and it is a major one (Stern \& Chew, 2003; Van Horne \& Wachowicz, 2009). As finance textbooks (e.g. Brealey et al., 2013; Ross et al., 2016) and conventional commercial wisdom recommend, it is, ceteris paribus, to the benefit of businesses to delay paying suppliers as long as possible in order to take advantage of a free source of finance. For example, Gitman et al. (1976, p.170) established that a key element of cash management strategies is to "Pay accounts payable [trade creditors] as late as possible without damaging the firm's credit rating and supplier relationships". However, as Cowton \& San-Jose (2017) argue, where this involves the breaking of a promise to pay by a certain date, the setting of unfair terms of trade because of power asymmetries, or a disconnect between the financial aspects and the underlying operations, ethical issues arise. A 'prompt' payment code might help address such issues, diminish the adverse consequences of slow payment, and improve the functioning of supply chains.

However, previous empirical literature on trade credit appears not to have examined the possible impact of payment codes. Not only does this reflect the lack of interest in the ethics of trade credit, but it is also likely a symptom of the decline of interest in the institutional detail of business finance as the subject was 'captured' by financial economics (Whitely, 1986). Thus, the research questions, and associated answers, on matters of trade credit tend to be framed in mainstream economic terms, which give limited insight into ethical issues. Such research examines issues such as the association of trade credit with macroeconomic variables (e.g. Meltzer, 1960; Emery, 1987; Fisman \& Love, 2003). Not surprisingly, empirical work on trade credit in this and similar veins appears to have increased since the Global Financial Crisis (e.g. Barrot, 2016; Carbó-Valverde et al., 2016; Hill et al., 2017; Fabbri \& Klapper, 2016; McGuinness et al., 2018), with one theme of such research 
being the dependency on trade credit as a source of finance during a period of financial constraint. Some papers analyse the trade credit situation in a particular country, for example the UK (Cheng \& Pike, 2003; Guariglia \& Mateut, 2006; Hill et al., 2017; Howorth \& Reber, 2003; Paul \& Boden, 2008; Wilson \& Summers, 2002). However, there is no empirical research that systematically studies trade credit from an ethical perspective, including the possible impact of a payment code - which is one of the topics recommended for research by Cowton \& San-Jose (2017).

Opportunities for studying payment codes arise in the UK because it has been an international pioneer of such schemes. Three successive codes, intended to improve the payment behaviour of trade debtors, have been promulgated by business organisations or government departments since 1991. Because the codes are voluntary, an analysis of whether signatories of payment codes are 'better' payers than non-signatories is possible. In this paper, to test this proposition we are also able to take advantage of some unique UK data which was required to be disclosed for a limited period of time in the early part of the $21^{\text {st }}$ century.

In addition to highlighting the importance of good payment practice for the smooth functioning of supply chains, this paper offers two principal contributions First, we examine whether payment codes make a difference. We compare the payment behaviour of companies that signed a payment code with those that did not. At first sight, signatories of payment codes seem not to be statistically better payers than non-signatories. However, a further level of analysis reveals that the signatories of one of the codes did indeed pay more quickly than both non-signatories and companies that were (unexpectedly) supposedly committed to a defunct code. Thus, we find evidence that a payment code can be beneficial. Second, the finding that some companies were claiming to adhere to a defunct code, yet on average were no quicker than non-signatories in paying their suppliers, suggests that there might be visible signals that indicate that a company might not be serious about adhering to the provisions of codes to 
which it has made a public commitment. This behaviour is identified with the notion of hypocrisy and discussed accordingly.

The remainder of the paper is organised as follows. The first main section provides the necessary background and develops the hypotheses. It provides an overview of previous research around codes of ethics and a comparison between payment codes and more general company codes. It also describes the relevant UK payment codes before the hypotheses are presented. The second section describes the data, variables and method. The third section presents the empirical results; a descriptive analysis that shows the take-up of payment codes is followed by the results of the hypothesis testing. The fourth section discusses the key findings, exploring the implications for thinking on both trade credit practice and the effectiveness of codes of ethics, as well as identifying limitations and making suggestions for further research. Finally, the Conclusion summarises the key contributions of the paper.

\section{Business codes, codes of payment practice and hypothesis development}

Prompt payment codes can be viewed as a special type of code of ethics (or conduct), which represent one of the most conspicuous features of business ethics in practice and one of the most discussed topics in the academic literature of business ethics. Much of the focus has been on corporate or business codes (by whatever name they are called), which Kaptein \& Schwartz (2008, p. 113) define as:

a distinct and formal document containing a set of prescriptions developed by and for a company to guide present and future behavior on multiple issues of at least its managers and employees toward one another, the company, external stakeholders and/or society in general.

They comment that such codes should be distinguished from more narrow codes, such as those that apply to just one function (e.g. finance: see Ahluwalia et al., 2018). Most large 
companies in developed countries now have a business code, as do many smaller (if not small) companies (Kaptein, 2017).

The important issue, though, is not how many firms have developed a code of ethics, but whether such codes make a difference. Scholars such as Dobson (2003) and Warren (1993) are sceptical, the latter believing that codes are "superficial and distracting answers to the question of how to promote ethical behaviour in corporate life" (Warren, 1993, p. 186). However, even supporters would not disagree with the proposition that codes can be useless or even misused. Codes can vary in quality (Garegnani et al., 2015) and, as Kaptein (2017) and Webley \& Werner (2008) counsel, a code on its own is never sufficient, though it might be regarded by many as necessary. Kaptein sums up his position in the following 'formula':

\section{Effectiveness $=$ Content $\mathrm{x}$ Embedding}

The importance of content for the effectiveness of a code is clear; it needs to cover and deal appropriately with the pertinent issues, which will tend to vary from one company to another, especially if in different industries (Crane \& Matten, 2016) or different countries. However, embedding is a much more complex matter, entailing many factors that go in to determining whether a good code is actually 'living' (Kaptein, 2017) - or not. Both Kaptein and Webley \& Werner provide useful summaries of the insights that have been collected through both their own experience and that of other researchers. Webley \& Werner note that it is the process by which the code is produced and used that matters; for example, who is involved in the development of the code, how they participate, whether the code is readable and couched in positive terms, how the contents are communicated, induction and training, managerial example and 'tone from the top', how the code is enforced, and whether it is reviewed and revised (see e.g. Adam \& Rachman-moore, 2004; Kaptein, 2004, 2017; Kaptein \& Schwartz, 2008; Kaptein \& Wempe, 1998; Norberg, 2009; Schwartz, 2004; Stevens, 2008; Webley \& Werner, 2008; Weeks \& Nantel, 1992). 
This paper is not directly concerned with the effectiveness of 'business codes', but the short review above provides useful background material for the consideration of payment codes. It also enables two conclusions of significance for the argument of the paper to be drawn at this point. First, contra the sceptics (or cynics), even though codes are not always effective, the identification of supportive factors shows that they can be useful in certain circumstances. Second, what systematic evidence there exists about the effectiveness of codes of ethics tends, like much of the debate, to focus on business codes rather than voluntary external codes produced for companies by third parties, such as NGOs or government departments. (There is, of course, a large literature on corporate governance codes, which are a prominent example of mandatory external code.) The payment codes examined in this paper are voluntary external codes. An example of research into a voluntary external code which had a broadly similar design to the current study is Cowton \& Thompson (2000), which compared the behaviour of banks that had signed the Statement by Banks on the Environment and Sustainable Development issued by UNEP (the United Nations Environment Programme) with those that had not.

Finally, it should be noted that general business codes tend to pay less attention to suppliers (and competitors) than to other stakeholders (Kaptein, 2004); and, to the extent that they mention them, they tend to focus on the responsibilities of suppliers (e.g. their employees' working conditions or environmental impact) rather than responsibility to them. A prompt payment code, if adopted, therefore complements the typical business code in terms of the treatment of suppliers. 


\section{UK payment codes}

Some of the factors that influence the effectiveness of a business code are of less relevance to the impact of a payment code, since it is a voluntary external code. Nevertheless, some of the characteristics supportive of the effectiveness of a business code still apply. For example, enforcement and communication matter. In this case a triple communication is involved. First, the developers of a payment code communicate it to companies and to society, hoping that firms will sign up. Second, signatories of a payment code indicate externally, by a logo and other means, that they are committed to a certain standard of behaviour. Finally, internally they need to make sure that relevant personnel know about the code if the commitments the company has made are to be met.

In the UK, payment codes have been in existence for nearly three decades. The current payment code in operation in the UK is the Prompt Payment Code, which was introduced in December 2008. Its development was supported by the Institute of Credit Management (ICM), on behalf of the (then) Department for Business, Enterprise and Regulatory Reform (BERR) of the UK Government. This was the third UK payment code. Code signatories undertake to:

1. Pay suppliers on time, within the terms agreed at the outset of the contract, without attempting to change payment terms retrospectively and without changing practice on length of payment for smaller companies on unreasonable grounds.

2. Give clear guidance to suppliers, providing them with clear and easily accessible guidance on payment procedures, ensuring there is a system for dealing with complaints and disputes which is communicated to suppliers, and advising them promptly if there is any reason why an invoice will not be paid to the agreed terms.

3. Encourage good practice, by requesting that lead suppliers encourage adoption of the code throughout their own supply chains. 
The Prompt Payment Code appears to have gained greater traction than the earlier codes, with many more signatories than previous incarnations - more than 2,400 as at December 2019. It is also notable that, in line with the advice for an effective business code, the Prompt Payment Code has an explicit enforcement mechanism; as at December 2019, 30 companies (though several were related members of the same corporate groups) were in a state of temporary suspension from the Code pending an improvement in their payment practices. $^{1}$

However, for reasons related to the availability of high-quality research data, as explained in the next section, and because of the discovery of an interesting phenomenon of significance to codes in general, it is the two previous codes that are the focus of this paper.

The first payment code was developed by the Confederation of British Industry (CBI), an umbrella organisation for employers. Entitled the Prompt Payers Code, it began operating in November 1991. The Code stated that responsible companies should:

- have a clear, consistent policy that they pay bills in accordance with contract;

- ensure that the finance and purchasing departments are both aware of this policy and adhere to it;

- agree payment terms at the outset of a deal and stick to them;

- not extend or alter payment terms without prior agreement; and

- provide suppliers with clear guidance on payment procedures.

Companies were also required to ensure that there was a system for dealing quickly with complaints and disputes and to advise suppliers without delay when invoices, or parts of invoices, were contested.

The CBI code was superseded in 1997 by the Better Payment Practice Code. The new code was not substantively different from the previous one, but it was clearer and more direct; and, while it was still voluntary, it enjoyed explicit government support, having been 
promulgated by the (then) Department of Trade and Industry (DTI). It urged all firms to adopt a responsible attitude to paying 'on time', or promptly, without specifying what that period should be. Signatories were to promise to:

- agree payment terms at the outset of a deal and stick to them;

- explain payment procedures to suppliers;

- pay bills in accordance with any contract agreed with the supplier or as required by law; and

- tell suppliers without delay when an invoice was contested, and settle disputes quickly.

An organisation that adopted the four-point code could apply to use the Better

Payment Practice logo which, it was intended, would send a clear signal to suppliers of its responsible position on prompt payment.

\section{Hypotheses}

The payment codes examined in this paper did not specify an actual payment period, which was left to the companies to determine; the codes refer to 'prompt' payment rather than speedy settling of invoices. There are two issues with this, one a matter of principle and the other a matter of practicality, when it comes to the empirical research. First, as explained by Cowton \& San-Jose (2017), the exploitation of customer power - particularly when a large company purchases supplies from a much smaller company - means that payment terms might be unduly extended and thus unfair. To pay 'promptly' in such circumstances does not amount to 'good' behaviour. Second, although companies sometimes disclose their standard payment terms, it is not possible to see the variety of payment terms that might, in fact, be incorporated into their contracts as buyer or seller and whether or not these are followed. For these reasons, we focus on speed of payment, which can be discovered - or more usually 
estimated - from published data in corporate financial statements. Our principal hypothesis is therefore as follows:

H1: Signatories of a payment code pay more quickly than non-signatories.

We only expected to see the DTI code being referred to, but we found that some companies claimed still to follow the old CBI code. The presence of the two codes in our data permits the second hypothesis:

H2: Signatories' speed of payment is independent of which code they signed.

\section{Method}

In order to test the hypotheses, it is necessary to have a measure of how quickly companies pay their suppliers. The 'payment days' figure for trade creditors or accounts payable is traditionally calculated in financial analysis as follows:

Average payment period $=$ Trade creditors $\mathrm{x} 365$

(in days) Cost of sales

This is not an accurate proxy, though, for two principal reasons. First, the denominator includes not only the cost of bought-in goods and services but also - for example in the case of a manufacturer - the cost of production labour and depreciation of machinery. Second, not all invoiced goods and - especially - services are included in the cost of sales (or cost of goods sold) figure. The difference in mix of costs between companies and, especially, between industries, means that - though it has a role to play, particularly in analysing trends in an individual company or comparing similar businesses - the ratio has significant shortcomings as a research proxy.

However, trade credit in the UK has been subject to various sporadic government initiatives, in addition to payment codes, over the past three decades. In a package of requirements introduced in 1997, Plcs (public limited companies) and Plc subsidiaries which 
qualified as 'large' companies were required, for a limited period as it transpired, to disclose a much more reliable and accurate estimate of trade creditor payment days. Contained in the now-withdrawn Companies Act 1985 (Directors' Report) (Statement of Payment Practice) Regulations 1997, it became mandatory for a time that the directors' report within the statutory annual report should make a quantitative statement relating the amount outstanding to suppliers to the total invoiced during the year. Thus, the traditional ratio, as shown in equation (1), was effectively modified to the following:

$$
\underset{\text { (in days) }}{\text { Average payment period }}=\frac{\text { Trade creditors value at the end of the year x } 365}{\text { Aggregate amount invoiced by suppliers during the year }}
$$

The numerator in equation (2) is the same as in equation (1). It can usually be found in a note to the balance sheet (or 'statement of financial position'). However, the denominator used by companies in calculating the payment days figure according to equation (2) is a much 'cleaner' figure than that used in the traditional proxy (1). It is not a number that is conventionally disclosed in financial statements. Its use in the calculation of the disclosed payment period figure gave a much more accurate and reliable indication of how quickly a company pays its suppliers. This figure is used in the testing of the hypotheses, taking advantage of the window of opportunity that the temporary regulation provided.

A crucial difference between researching external codes and business codes is that the content of an external code is consistent for signatories/adopters, whereas business codes are apt to differ in the quality of their content, thus confounding empirical results. However, in the case of an external code there is no difference in content between companies, so a simple dummy variable can be used, to indicate whether a company has signed up to a payment code ( 1 = signatory, $0=$ non-signatory). In addition to the payment period figure, a further requirement of the 1997 Regulations was that the companies should disclose in the directors' report within their annual report whether they followed any code or standard on payment 
practice and, if so, the name of the code or standard (and how to get copies of the code). Data on whether a company was a code signatory, together with the payment period figures, were therefore hand-collected from annual reports.

Finally, given the focus of the 1997 Regulations on large companies, and because of their economic importance, the sample was taken from the FTSE All-Share Constituents \& Weightings data, which comprised:

- the FTSE 100 (consisting of the largest 100 UK companies by full market value, i.e. before the application of any investment weightings),

- the FTSE 250 (consisting of the next 250 UK companies ranked by full market value), and

- the FTSE SmallCap (consisting of the UK companies within the FTSE All-Share which are not large enough to be constituents of the FTSE 350 (i.e. FTSE 100 plus FTSE 250).

We initially selected: $100 \%$ of FTSE 100 firms; ${ }^{2} 20 \%$ of FTSE 250 firms; and $14 \%$ of FTSE SmallCap. The sample for FTSE 250 and SmallCap was selected randomly using a systematic method after listing the population in alphabetical order. Replacement was made if 2007 accounts were not available. Thus, a sample of 200 firms was selected, balanced equally between the very largest companies (FTSE100) and others. The sample accounts for approximately $85 \%$ of the capitalization of UK firms at the time. ${ }^{3}$ Firms that did not use trade credit, such as banks and investment trusts, were then excluded, which reduced the sample to 138 companies. 


\section{Findings}

Table 1 provides initial descriptive statistics regarding the sample.

\section{INSERT TABLE 1 HERE}

The first notable finding is that only 12 firms disclosed that they had signed a payment code - less than $10 \%$ of the sample that used trade credit. Although it was not an objective of the research to ascertain how widely a payment code had been adopted, this finding would suggest that, at the time on which the study focuses, prompt payment codes were not very successful, in spite of the time they had been in existence in the UK. Adoption might not be sufficient, but it is at least necessary for a code's effectiveness. However, although the period to which the data relate imply a problem, the December 2019 figures quoted earlier in the paper for the current code, suggest that this issue, at least, is in the process of being overcome.

It is particular striking in the study's data that only two companies from the FTSE 250 and FTSE SmallCap, combined, were signatories. However, the corollary of this is that 10 of the 12 signatories (more than 80\%) were members of the FTSE 100, i.e. very large firms.

However, we did encounter anecdotal evidence that some companies might have signed up to a code without disclosing the fact in the directors' report, contrary to the 1997 Regulations. Moreover, disclosure of signing of a code was more common amongst the FTSE 100. Thus, the economic significance of a payment code might be somewhat greater than an initial reading of Table 1 might suggest. Nevertheless, only a 1 in 7 minority of FTSE 100 companies that used trade credit disclosed that they were signatories.

Since only two of the sampled FTSE 250 and FTSE SmallCap companies were found to be signatories, it was decided to focus the statistical analysis on FTSE 100 companies, where no sampling was involved. These are the very largest UK-listed companies. Table 2 presents the findings for this group of companies. 


\section{INSERT TABLE 2 HERE}

As can be seen, code signatories paid more quickly than non-signatories, as expected. However, using Mann-Whitney $\mathrm{U}^{4}$ in a one-tailed test of significance (since $\mathrm{H} 1$ is a directional hypothesis), $\mathrm{p}=.91$. In other words, the difference was only marginally significant at the $10 \%$ level and therefore the hypothesis that 'signatories of a payment code pay more quickly than non-signatories' should ideally be rejected, assuming that a higher level of significance is desirable. Although the difference between signatories and non-signatories in Table 2 might at first sight have seemed significant, it should be noted that the standard deviation of non-signatories is relatively large. We return to the implication of this point in the Discussion.

However, as we were gathering the data, we noticed something unexpected; there were still companies declaring that they had signed the CBI code, even though it had been replaced by the DTI code ten years earlier. Indeed, the signatories in our FTSE 100 sample were divided equally between the CBI and the DTI codes. It was surprising that firms continued to refer to it and we decided to see if there was a difference between the two sets of signatories: hence hypothesis H2. The results are shown in Table 3.

\section{INSERT TABLE 3 HERE}

The difference between the two types of signatories is stark: DTI Code signatories averaged 17.2 days, whereas CBI Code signatories averaged 32.0 days. Using a two-tailed test (since $\mathrm{H} 2$ is non-directional), $\mathrm{p}=.979$, so the difference is clearly significant at (more than) the 5\% level. Moreover, as might be expected when comparing the relevant information in Table 3 and Table 2, there is no statistically significant difference between CBI signatories (32.0 days) and non-signatories (33.3 days). We discuss the implications of this for codes of 
ethics in general below. However, as a conclusion to this section, it is worth highlighting that we would be able to accept a modified form of the original hypothesis, H1, namely:

H3: Signatories of a current payment code pay their suppliers significantly more quickly than companies that have not signed that code.

\section{Discussion}

There are signs that the ethics of trade credit is now being taken seriously in the academic literature (Cowton \& San-Jose, 2017). Delaying payment to suppliers has long been recognised, but in purely instrumental terms, in commercial wisdom and finance textbooks as an important aspect of the financial management of firms. However, more recently, slow or late payment has attracted sustained public criticism, which has prompted various policy initiatives in the UK over the past 20-30 years. Three successive voluntary codes have been launched (in 1991, 1997 and 2008) to encourage better payment practice and so improve the operation of supply chains. There are signs that other countries are following this lead, especially as the problem of delayed settling of invoices has been brought into sharper focus by the Global Financial Crisis. For example, the Australian state of Victoria has introduced the Fair Payment Code and Ireland has its own Prompt Payment Code. Payment behaviour, and codes of payment practice in particular, therefore seem to be an area of growing importance.

The key question is whether such codes have an impact - a familiar issue for codes of ethics in general. In the case of the literature on business codes, it is clear that there can be no impact without their creation. In the case of payment codes, which are an example of a voluntary external code, the equivalent necessary condition is the extent of adoption. At the time to which the data in this paper relate, which was nevertheless more than fifteen years 
after the first payment code had been introduced in the UK, adoption seems rather low, with only a minority of the largest companies indicating their commitment, thus implying limited influence. However, the current Prompt Payment Code has attracted many more signatories (in excess of 2,400), which not only suggests that there is potential for impact but makes it even more important that evidence is gathered to determine whether such codes do make a difference - as we have, with positive results, in this study.

Taking advantage of a high quality proxy that was available for a period of time, we were able to analyse whether code signatories paid more quickly than non-signatories. We found a difference, but it was not large enough for us to accept the hypothesis of quicker payment, which would seem to undermine the case for payment codes; either that, or something would need to happen to increase their effectiveness.

There could be several factors underlying this result, some of them statistical in nature. One might be the small samples; we focused on the most important companies, the FTSE 100, and there were only ten signatories to compare with non-signatories. Another factor is probably the high standard deviation of payment days for non-signatories. In other words, even though the average length of time taken by FTSE 100 non-signatories was higher than that for signatories, some non-signatories settled their invoices relatively quickly. This mirrors a result found by Cowton \& Thompson (2000), that some banks appeared to behave in a way which, on the face of it, seemed to be consistent with the tenets of the UNEP Statement by Banks on the Environment and Sustainable Development, yet they did not take the step of formally adopting it. One reason identified was that some senior bankers were unaware of the Statement. Similarly, lack of awareness might be an explanation for some relatively quickpaying companies not signing a payment code. Another reason might be that, although the companies paid their debts relatively quickly and knew about a code, they were not willing to adhere completely to the code. For example, the two codes examined in this paper were 
concerned with prompt payment, and it is possible that a company might not be willing to commit to paying all companies promptly for the foreseeable future, even if its current average payment period is relatively good. Thus, the signing of a payment code might still provide a useful signal to suppliers, even if the difference in speed of payment between signatories and non-signatories at some point is not statistically significant; it is a sign of apparent commitment.

However, our results showed that simply being a signatory of a code was not a reliable signal of being a good payer - as critics of codes would have expected. Further analysis of unexpected variety in our data, though, provided additional insights, not only into payment codes but, we suggest, potentially into codes in general too. As shown by the findings, signatories of the more recent code were significantly quicker payers than signatories of the older code who, in turn, were not discernibly different from non-signatories. Thus, in addition to some non-signatories behaving, at least in some respects, like (good) signatories, the data used for testing $\mathrm{H} 1$ were further affected by signatories that were behaving like nonsignatories. The clear conclusion from this is that a payment code does tend to make a difference, but only if it is a recent one. What we discovered merits some further discussion.

The question is: what was going on with the signatories of the old code, beyond not paying any more quickly, on average, than non-signatories? As noted earlier, the DTI code replaced the CBI code, and it seems strange that some companies continued to refer publicly to the CBI code. Perhaps they were keen to appear ethical - although the number of nonsignatories suggests that reputational damage, at least at that time, would have been limited. On the other hand, perhaps they had not noticed that the CBI code had been superseded. Thus, lack of awareness might have a role to play again, but in a different way. It should be noted, though, that the statistical analysis suggests they were not actively following the old code, so it was not a matter of engaging in exemplary payment behaviour without realising that a 
newer code was in operation. Indeed, given the routine, not to say ritualistic, nature of some aspects of annual corporate reporting, it is possible that reference to the old payment code was simply carried over from one year's directors' report to the next. This might have been without any deliberate intention of misleading. Nevertheless, it - or any other explanations still involve a company inappropriately helping itself to the trappings of ethically better or admirable behaviour without actually engaging in it.

Thus, whether deliberately or unintentionally on the part of the companies concerned, the old code was acting as window dressing. Another word would be hypocrisy, the etymological root of which refers to the masks used in Greek drama. The mask is a way of covering up, of concealing, what one is really like, instead assuming a particular persona (which can mean 'mask' in Latin). Hypocrisy can take several different forms but it can be argued that it is, fundamentally, a failure to take morality seriously (Crisp \& Cowton, 1994); such a depiction seems to fit the old CBI code signatories who appear not to have been taking the code seriously, even if they once did.

Such 'forgetfulness' or deception gives misleading signals to suppliers and other stakeholders and undermines the more general payment code 'project'. However, the results of this paper suggest that there might be signs when a company is not taking a code seriously, which opens up an avenue for potentially fruitful research. In this case, the indication that the signal of signing up to a code might be misleading, was that the code they referred to was out of date, having been superseded by another code several years before.

While many of the factors that influence the likely effectiveness of a corporate or business code, discussed earlier, are largely invisible to external stakeholders (e.g. development process, communication to employees, training etc), perhaps there are useful indicators that can be identified. For example, while a degree of consistency over time can be helpful, is the latest version of the code (assuming it is a dated document, as many are) a very 
old one? Does the language around the code (e.g. on the website) ever change? Do all the hyperlinks within the web-based version still work? Is the statement of support, if there is one, from the current $\mathrm{CEO}$ or chair of the board of directors? The aim here is not to generate a comprehensive list of such possibilities, but, prompted by our findings, to suggest an agenda for further research, namely: what externally visible signs can provide an indication that a company might not be taking its code of ethics seriously?

Other suggestions for further research emerge more directly from the limitations of the current paper.

First, the sample size for signatories was not large, thus closing off possibilities for more sophisticated statistical analysis (though it should be noted that there were no significant differences between signatory and non-signatory firms in terms of industry sector), while controlling for other variables. Nevertheless, in spite of the small number of FTSE 100 signatories, statistically significant results of considerable interest were found, once the distinction between the two codes was factored in.

Second, the data are not recent, although, in the absence of similar studies, the analysis still provides a novel contribution to the literature (see Cowton, 2019). We were able to take advantage of what turned out to be a temporary disclosure requirement in the UK, which provided a much more valid measure of payment days than is usually possible using company accounts. We did do some analysis using the traditional financial analysis proxy, but the correlation with the much better proxy that we have been able to use here was so poor that we decided not to use it to extend the time period under consideration.

Another feature of the data is that, notwithstanding its limitations, it happened to reveal an interesting phenomenon of significance to the general literature on codes of ethics, 
which we believe is worthy of further thought and empirical investigation along the lines indicated.

To the authors' knowledge, this is the first paper to examine the effectiveness of payment codes. With the recent and current activity around payment codes, there will be opportunities for further research using more recent data. A study of the effectiveness of the current UK code, the Prompt Payment Code, could be undertaken, examining the level of adoption and testing whether there is a difference in payment days between signatories and non-signatories, as here. However, given the much larger number of signatories than under previous codes, when testing for differences in payment behaviour between signatories and non-signatories it should be possible to undertake more sophisticated statistical analysis to examine whether factors such as date of joining, company size or industry ${ }^{5}$ are significant influences, whilst controlling for various other factors that might be expected to affect payment days (e.g. leverage, liquidity or profitability). The greater number of signatories, while there are still many non-signatories, also opens up opportunities for seeking to explain statistically the differences between the two by examining the antecedents of signing the Code. Finally, the growing number of firms that have been suspended from the Prompt Payment Code register is providing an interesting set of data that might feature in future studies.

Similar research questions might also be asked in other countries as payment codes become operational there, although the dependent variable might have to be measured by the less satisfactory, traditional method of calculating payment days.

Finally, it is worth noting that companies are not the only signatories, for public sector organisation have also been known to adopt a payment code; they could also be subjects of research It would also be interesting to gain the insights of participants: finance staff at 
signatory and non-signatory companies (e.g. why sign or not sign, how implemented?) and suppliers (e.g. are they aware of the code, how do they use it?).

\section{Conclusion}

Codes in general are a common feature of attempts to make companies behave - or appear better. The promptness or speed with which companies pay their suppliers is an area of increasing concern internationally, with some governments beginning to follow the UK's example in introducing voluntary payment codes. As the first empirical study of the effectiveness of payment codes, this paper makes a significant contribution to the underresearched area of trade credit ethics. First, even though sample size might be expected to limit statistical power, the findings show that a payment code can be associated with significantly faster settlement of debts, with consequent benefits for suppliers, their stakeholders and supply chains. Second, however, we found evidence of some companies apparently not taking seriously the payment code to which they were supposedly committed. This was revealed by their claiming to follow an out-of-date code yet paying no more quickly, on average, than non-signatories. This led to a discussion centred on the notion of hypocrisy and how observers might discern indications that a company is not taking seriously the commitments signalled by a code. Overall, then, when it comes to the question of effectiveness, there is evidence of interest to both supporters and critics of codes.

Finally, as the first empirical study of payment codes, this paper lays the foundation for future studies that should be able take advantage of the greater amount of data that is developing, in the UK and elsewhere. It is hoped that the present study itself, and our various suggestions for building on it, encourage and help to guide future research into how payment 
codes might help to reduce slow payment of debts in supply chains, the importance of which is, rightly, increasingly being recognised by policymakers.

\section{Notes}

1 Further information about the current Prompt Payment Code can be found at http://www.promptpaymentcode.org.uk

2 There were actually 102 firms in the FTSE ' 100 ' at the time, but Royal Dutch Shell B and Schroders N/V were eliminated because we did not have the relevant information about them.

3 The sample is significant at the $95 \%$ level with an error of $3.77 \%$.

4 SPSS Version 24 automatically selects the appropriate test, given the distribution of the data.

5 For examples, do large retailers (especially supermarkets, with their buying power) delay supplier payments if they are not signatories - even though they should be amongst the quickest payers because they make their own sales for cash or near-cash (see Cowton \& San-Jose, 2017)? 


\section{References}

Adam, A.M. and Rachman-moore, D. (2004) 'The methods used to implement an ethical code of conduct and employee attitudes', Journal of Business Ethics, Vol. 54, No. 3, pp.225244.

Ahluwalia, S., Ferrell, O.C., Ferrell, L. and Rittenburg, T.L. (2018) 'Sarbanes-Oxley Section 406 Code of Ethics for senior financial officers and firm behavior', Journal of Business Ethics, Vol. 151, No. 3, pp.693-705.

Barrot, J.N. (2016) 'Trade credit and industry dynamics: evidence from trucking firms', Journal of Finance, Vol. 71, No. 5, pp.1975-2016.

Brealey, R.A., Myers, S.C. and Allen, F. (2013) Principles of Corporate Finance, $11^{\text {nd }}$ Edition, McGraw-Hill Irwin, New York.

Carbó-Valverde, S., Rodríguez-Fernández, F. and Udell, G.F. (2016) 'Trade credit, the financial crisis, and SME access to finance', Journal of Money, Credit and Banking, Vol. 48, No. 1, pp.113-143.

Cheng, N.S. and Pike, R. (2003) 'The trade credit decision: Evidence of UK firms', Managerial and Decision Economics, Vol. 24, Nos. 6/7, pp.419-438.

Cowton, C.J. (2019), 'Making a contemporary contribution using old data: reflections on delayed doctorates', International Journal of Management Education, Vol. 17, No. 1, pp.77-84.

Cowton, C.J. and San-Jose, L. (2017) 'On the ethics of trade credit: Understanding good payment practice in the supply chain', Journal of Business Ethics, Vol. 140, No. 4, pp.673-685. 
Cowton, C.J. and Thompson, P. (2000) 'Do codes make a difference? The case of bank lending and the environment', Journal of Business Ethics, Vol. 24, No. 2, pp.165-178.

Crane, A. and Matten, D. (2016) Business Ethics: Managing Corporate Citizenship and Sustainability in the Age of Globalization, $4^{\text {th }}$ Edition, Oxford University Press, Oxford.

Crisp, R. and Cowton, C. (1994) 'Hypocrisy and moral seriousness', American Philosophical Quarterly, Vol. 31, No. 4, pp.343-349.

Dobson, J. (2003) 'Why ethics codes don't work', Financial Analysts Journal, Vol. 59, No. 2, pp.29-34.

Emery, G. (1987) 'An optimal financial response to variable demand', Journal of Financial and Quantitative Analysis, Vol. 22, No. 2, pp.209-225.

Fabbri, D. and Klapper, L.F. (2016) 'Bargaining power and trade credit', Journal of Corporate Finance, Vol. 41, pp.66-80.

Fisman, R. and Love, I. (2003) 'Trade credit, financial intermediary development and industry growth', Journal of Finance, Vol. 58, No. 1, pp.353-374.

Garegnani, G.M., Merlotti, E.P. and Russo, A. (2015) 'Scoring firms' codes of ethics: An explorative study of quality drivers', Journal of Business Ethics, Vol. 126, No. 4, pp.541-557.

Gitman, J., Forrester, D.K. and Forrester, J.R. (1976) Principles of Managerial Finance, Harper and Row, New York.

Guariglia, A. and Mateut, S. (2006) 'Credit channel, trade credit channel and inventory investment: Evidence from a panel of UK firms', Journal of Banking \& Finance, Vol. 30, No. 10, pp.2835-2856. 
Hill, M.D., Kelly, G.W., Preve, L.A. and Sarria-Allende, V. (2017) 'Trade credit or financial credit? An international study of the choice and its influences', Emerging Markets Finance and Trade, Vol. 53, No. 10, pp.2318-2332.

Howorth, C. and Reber, B (2003) 'Habitual late payment of trade credit: An empirical examination of UK small firms', Managerial and Decision Economics, Vol. 24, Nos. 6/7, pp.471-482.

Kaptein, M. (2004) 'Business codes of multinational firms: What do they say?', Journal of Business Ethics, Vol. 50, No. 1, pp.13-31.

Kaptein, M. (2017) The Living Code: Embedding Ethics Into the corporate DNA, Routledge, Abingdon.

Kaptein, M. and Schwartz, M. (2008) 'The effectiveness of business codes: A critical examination of existing studies and the development of an integrated research model', Journal of Business Ethics, Vol. 77, No. 2, pp.111-127.

Kaptein, M. and Wempe, J. (1998) 'Twelve Gordian Knots when developing an organizational code of ethics', Journal of Business Ethics, Vol. 17, No. 8, pp.853-869.

McGuinness, G., Hogan, T. and Powell, R. (2018) 'European trade credit use and SME survival', Journal of Corporate Finance, Vol. 49, pp.81-103.

Meltzer, A. (1960) 'Mercantile credit monetary policy, and size of firms', Review of Economics and Statistics, Vol. 42, No. 4, pp.429-437.

Norberg, P. (2009) 'I don't care that people don't like what I do - business codes viewed as invisible or visible restrictions', Journal of Business Ethics, Vol. 86, No. 2, pp.211-225.

Paul, S. and Boden, R. (2008) 'The secret life of UK trade credit supply: Setting a new research agenda', British Accounting Review, Vol. 40, No. 3, pp.272-281. 
Ross, S.A., Westerfield, R.F., Jaffe, J. and Bradford, J. (2016) Corporate Finance, $11^{\text {th }}$ Edition, McGraw Hill, New York.

Schwartz, M. (2004) 'Effective corporate codes of ethics: Perceptions of code users', Journal of Business Ethics, Vol. 55, No. 4, pp.321-341.

Sorell, T. and Hendry, J. (1994) Business Ethics, Butterworth Heinemann, Oxford.

Stern, J.M. and Chew D.H., Eds. (2003) The Revolution in Corporate Finance, 4th Edition, Blackwell, Oxford.

Stevens, B. (2008) 'Corporate ethical codes: Effective instruments for influencing behavior', Journal of Business Ethics, Vol. 78, No. 4, pp.601-609.

Van Horne, J.C. and Wachowicz, J.M. (2009) Fundamentals of Financial Management, $13^{\text {th }}$ Edition, Prentice Hall, Upper Saddle River.

Warren, R.C. (1993) 'Codes of ethics: Bricks without straw', Business Ethics: A European Review, Vol. 2, No. 4, pp.185-191.

Webley, S. and Werner, A. (2008) 'Corporate codes of ethics: Necessary but not sufficient', Business Ethics: A European Review, Vol. 17, No. 4, pp.405-415.

Weeks, W.A. and Nantel, J. (1992) 'Corporate codes of ethics and sales force behavior: A case study', Journal of Business Ethics, Vol. 11, No. 10, pp.753-760.

Whitely, R. (1986) 'The transformation of business finance into financial economics: The roles of academic expansion and changes in U.S. capital markets', Accounting, Organizations and Society, Vol. 11, No. 2, pp.171-192.

Wilson, N. and Summers, B. (2002) 'Trade credit terms offered by small firms: Survey evidence and empirical analysis', Journal of Business Finance \& Accounting, Vol. 29, Nos. 3/4, pp.317-351. 
Table 1. The incidence of payment codes in the sample

\begin{tabular}{|c|c|c|c|c|}
\hline & FTSE100 & FTSE250 & FTSESmallCap & Total \\
\hline Signatories & 10 & 1 & 1 & 12 \\
\hline \multirow[t]{2}{*}{ Non-signatories } & $\underline{58}$ & $\underline{32}$ & $\underline{35}$ & $\underline{125}$ \\
\hline & 68 & 33 & 36 & 137 \\
\hline$\%$ with code & $14.7 \%$ & $3.0 \%$ & $2.8 \%$ & $8.8 \%$ \\
\hline No trade credit & 32 & $\underline{17}$ & $\underline{\underline{14}}$ & 63 \\
\hline Total companies & 100 & 50 & 50 & 200 \\
\hline$\%$ sampled & $100 \%$ & $\underline{\underline{20 \%}}$ & $\underline{\underline{14 \%}}$ & \\
\hline
\end{tabular}


Table 2. Initial analysis of FTSE100 companies

\begin{tabular}{l|c|c} 
& $\begin{array}{c}\text { Code signatories } \\
\mathbf{1 0} \text { firms }\end{array}$ & $\begin{array}{c}\text { Code non-signatories } \\
\mathbf{5 8} \text { firms }\end{array}$ \\
\cline { 2 - 3 } & Payment days & Payment days \\
\hline Mean & 24.6 & 33.3 \\
\hline Std. deviation & 11.0 & 17.2 \\
\hline
\end{tabular}


Table 3. Further analysis of FTSE100 companies

\begin{tabular}{l|c|c} 
& $\begin{array}{c}\text { Signatories of DTI Code } \\
\text { 5 firms }\end{array}$ & $\begin{array}{c}\text { Signatories of CBE Code } \\
\text { 5 firms }\end{array}$ \\
\hline & Payment days & Payment days \\
\hline Mean & 17.2 & 32.0 \\
\hline Std. deviation & 8.1 & 8.3 \\
\hline
\end{tabular}

